\title{
FRICTION FORCES IN NUMERICAL SIMULATIONS OF KINEMATICAL JOINTS OF MECHANICAL SYSTEMS
}

\author{
Calin-Octavian Miclosina, Vasile Cojocaru *, Daniel-Gheorghe Vela \\ Babeş-Bolyai University \\ Faculty of Engineering \\ Traian Vuia Square, No. 1-4, 320085 Resita, Romania \\ * Corresponding author. E-mail: vasile.cojocaru@ ubbcluj.ro
}

\begin{abstract}
The paper presents a way of estimation, by simulation, of friction forces that occur in the kinematical joints of mechanical systems. Friction forces between planar surfaces, in revolute joints, and in spherical joints are computed, and the results are compared with the values achieved from simulation. SolidWorks software is used for the simulation process.
\end{abstract}

Keywords: friction force, kinematical joint, simulation, SolidWorks.

\section{Introduction}

Friction forces occur to operating mechanical systems, as a result of components interaction, or of mechanical system interaction with external factors.

The numerical simulation is a frequently used instrument for the analysis of mechanical structures behavior in statical or dynamical conditions [11], [12], [13], [14], [16], [17].

For an accurate numerical simulation of real mechanical systems operation, all the conditions have to be considered - including the contact pressure [2], [3], and the friction phenomenon.

The influence of friction forces was studied by numerical simulation for different mechanical systems [15], for fixed robot structures [1], [8], or for mobile robot structures [4], [5], [18], [19].

The friction phenomenon causes local contact erosion, which influences the machine parts operation lifetime [6].

Numerical models, considering the friction forces, are used in the field of robotic surgery, where high accuracy is required [7].

Recently, new methods of studying the friction influence are used, for example the method based on neural networks [9].

The paper presents some cases of friction force calculus for different kinematical joints, motion simulations of the kinematical joints, and the numerical determination of friction forces. The values resulted from calculus are compared with those achieved from simulations, where certain peak values were neglected, being out of usual range. Both for calculus and for simulations, the same friction coefficients are used, given by the software, and according to [10] and [20]. For numerical simulations, SolidWorks software is used.

\section{Friction Forces between Planar Surfaces}

The simple case of a cube moving on a base plane surface is considered, as shown in figure 1. The forces that occur are as follows: the traction force $\mathrm{F}$, the weight $\mathrm{W}$, the normal reaction $\mathrm{N}$, and the friction force $\mathrm{F}_{\mathrm{f}}$. The cube is set to move at a constant speed $\mathrm{v}$.

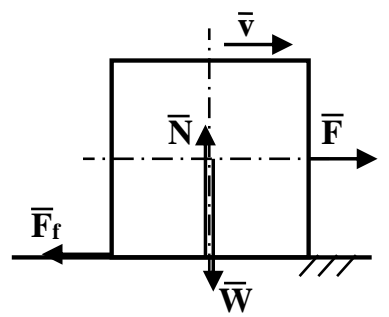

Fig. 1. Friction force $F_{f}$ occurring between the cube and the plane surface.

The cube's material is considered to be cast carbon steel, with the density $\rho=7800\left[\mathrm{~kg} / \mathrm{m}^{3}\right]$; in order to ease the calculus, the cube is set to a volume $\mathrm{V}=1\left[\mathrm{~m}^{3}\right]$, which means that the cube has the mass:

$$
\mathrm{m}=\rho \cdot \mathrm{V}=7800 \cdot 1=7800[\mathrm{~kg}] .
$$

The cube weight is:

$$
\mathrm{W}=\mathrm{m} \cdot \mathrm{g}=7800 \cdot 9.806=76487[\mathrm{~N}]
$$

The expressions of friction force between the cube and the base, in static and kinematical conditions respectively, are as follows:

$$
\begin{aligned}
& \mathrm{F}_{\mathrm{fs}}=\mu_{\mathrm{s}} \cdot \mathrm{N}=\mu_{\mathrm{s}} \cdot \mathrm{W}=0.3 \cdot 76487=22946[\mathrm{~N}] \\
& \mathrm{F}_{\mathrm{fk}}=\mu_{\mathrm{k}} \cdot \mathrm{N}=\mu_{\mathrm{k}} \cdot \mathrm{W}=0.25 \cdot 76487=19122[\mathrm{~N}]
\end{aligned}
$$

where: $-\mu_{\mathrm{s}}=0.3$ is the static friction coefficient in dry friction conditions for steel, provided by SolidWorks software; 
- $\mu_{\mathrm{k}}=0.25$ is the kinematic friction coefficient in dry friction conditions for steel, provided by SolidWorks software;

$-\mathrm{N}=\mathrm{W}$ is the normal reaction force between the cube and the base surface.

The 3D model of the cube, accomplished in SolidWorks software, is presented in fig. 2.

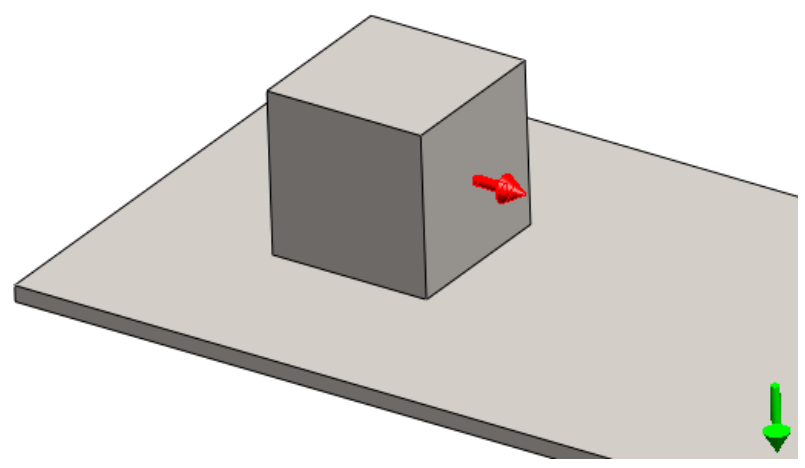

Fig. 2. 3D model of a cube moving on a planar surface.

The cube material, as well as the base material, is Cast Carbon Steel, chosen from SolidWorks materials library.

In SolidWorks Motion module, between the cube and the base there is defined a Solid Body Contact, with the same kinematic friction coefficients used in relations (3) and (4).

The cube is set to move with a speed of 2000 $[\mathrm{mm} / \mathrm{s}]$, in a period of $0.5[\mathrm{~s}]$.

In order to re-create the real conditions, the gravity is applied in SolidWorks Motion module.

Figure 3 shows the variation of friction force, obtained as a simulation result. The friction force value varies very fast at the beginning of motion, because the rest state of the cube instantly modifies to motion state in the simulation.

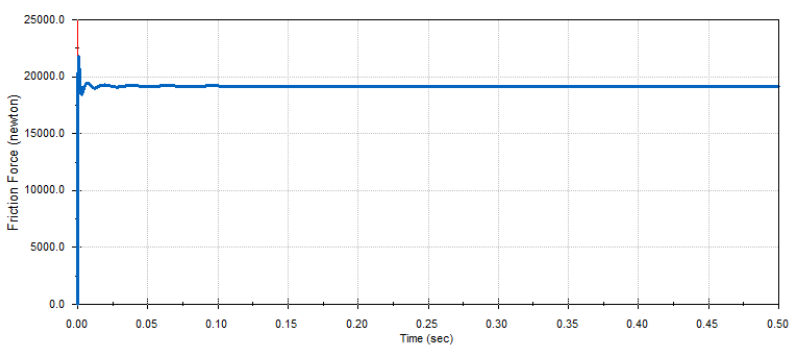

Fig. 3. The variation of friction force between the cube and the base in simulation.

The friction force obtained by simulation has a value of $21704[\mathrm{~N}]$ in static conditions, at the beginning of motion, close to the computed value of 22946 [N], from calculus (3), and a stabilized value in motion of around $19120[\mathrm{~N}]$, very close to the computed value of $19122[\mathrm{~N}]$, from calculus (4).

\section{Joints}

3. Friction Forces in Revolute Kinematical

The next case studied is that of friction forces which occur between cylindrical surfaces.

The forces that occur are as follows: the axial force $F_{a}$, the tangential force $F_{t}$, the weight $W$, the normal reaction $\mathrm{N}$, and the friction force $\mathrm{F}_{\mathrm{f}}$, as shown in fig. 4. The shaft is set to move with a constant angular speed $\omega$, due to a torque $\mathrm{M}_{\mathrm{t}}$.

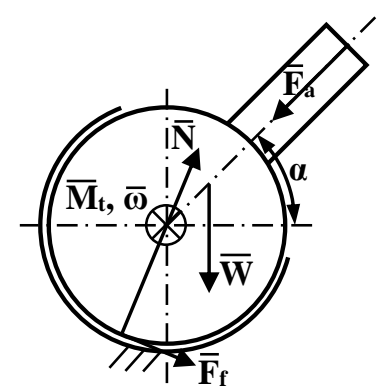

Fig. 4. Forces acting on the shaft of the revolute joint.

The material of the components is considered to be alloy steel, with the density $\rho=7700\left[\mathrm{~kg} / \mathrm{m}^{3}\right]$. The shaft together with the lever have the mass of $12.87 \cdot 10^{-3}[\mathrm{~kg}]$.

The expressions of friction force between the shaft and the bearing, in static and kinematical conditions respectively, are as follows:

$$
\begin{aligned}
\mathrm{F}_{\mathrm{fs}} & =\mu_{\mathrm{s}} \cdot \mathrm{N}=\mu_{\mathrm{s}}(\mathrm{W}+\mathrm{F})=0.08 \cdot 10.129= \\
& =0.810[\mathrm{~N}] \\
\mathrm{F}_{\mathrm{fk}} & =\mu_{\mathrm{k}} \cdot \mathrm{N}=\mu_{\mathrm{k}}\left[\mathrm{F}^{2}+\mathrm{W}^{2}+2 \mathrm{FW} .\right. \\
& \cdot \cos (90-\alpha)]^{1 / 2}=0.05 \cdot 10089=0.504[\mathrm{~N}]
\end{aligned}
$$

where: $-\mu_{\mathrm{s}}=0.08$ is the static friction coefficient in greasy friction conditions for steel, provided by SolidWorks software;

- $\mu_{\mathrm{k}}=0.05$ is the kinematic friction coefficient in greasy friction conditions for steel, provided by SolidWorks software;

- $\mathrm{N}$ is the normal reaction force between the shaft and the bearing; it is computed in relation (5) for the angle $\alpha=90^{\circ}$, and in relation (6) for the angle $\alpha=45^{\circ}$, as follows:

$$
\begin{aligned}
\mathrm{N} & =\left[\mathrm{F}^{2}+\mathrm{W}^{2}+2 \mathrm{FW} \cos (90-\alpha)\right]^{1 / 2}=\left[10^{2}+\right. \\
& \left.+0,126^{2}+2 \cdot 10 \cdot 0.126 \cdot \cos (90-45)\right]^{1 / 2}= \\
& =10.089 \mathrm{~N}
\end{aligned}
$$

Figure 5 shows the geometrical model of a revolute kinematical joint.

The components material is Alloy Steel, chosen from SolidWorks materials library. In SolidWorks Motion module, between the shaft and the bearing there is defined a Solid Body Contact, with the same kinematic friction coefficients used in relations (5) and (6).

The shaft is set to move with an angular speed of $\pi / 3[\mathrm{rad} / \mathrm{s}]$, e.g. $120[\% \mathrm{~s}]$, in a period of $0.5[\mathrm{~s}]$.

The gravity is also applied in this case. 


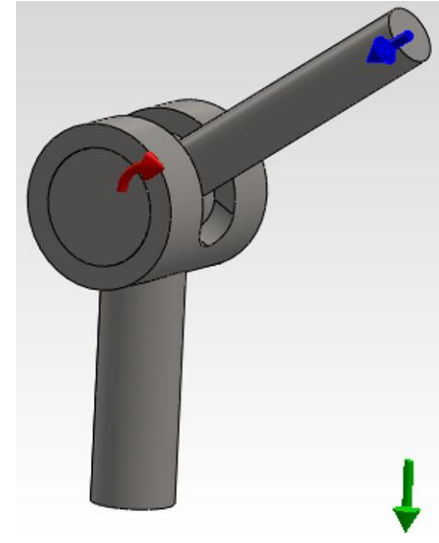

Fig. 5. 3D model of a revolute kinematical joint.

Figure 6 shows the variation of friction force, obtained as a simulation result.

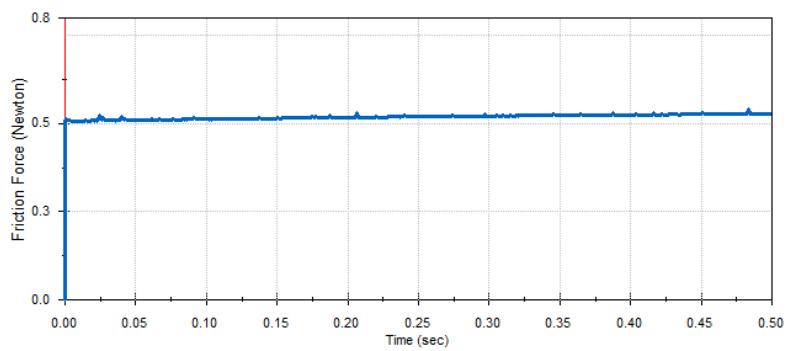

Fig. 6. The variation of friction force between the shaft and the bearing in simulation.

The friction force obtained by simulation has a value of $0.787[\mathrm{~N}]$ in static conditions, at the beginning of motion, close to the computed value of $0.810[\mathrm{~N}]$ from calculus (5), and a value in motion of $0.523[\mathrm{~N}]$ for the position $\alpha=45^{\circ}$, close to the computed value of $0.504[\mathrm{~N}]$ from calculus (6). The exact values of friction force in simulation are taken from a .csv file provided by SolidWorks software.

\section{Joints}

\section{Friction Forces in Spherical Kinematical}

The scheme of disposal of forces in this case is similar to the scheme of the previous case, as presented in fig. 4.

The expressions of friction force between the sphere and the spherical shell, in static and kinematical conditions respectively, are as follows:

$$
\begin{aligned}
\mathrm{F}_{\mathrm{fs}} & =\mu_{\mathrm{s}} \cdot \mathrm{N}=\mu_{\mathrm{s}}\left(\mathrm{W}+\mathrm{F}_{\mathrm{a}}\right)=0,05 \cdot 10.43= \\
& =0.522[\mathrm{~N}] \\
\mathrm{F}_{\mathrm{fk}} & =\mu_{\mathrm{k}} \cdot \mathrm{N}=\mu_{\mathrm{k}}\left[\mathrm{F}_{\mathrm{a}}^{2}+\mathrm{W}^{2}+2 \mathrm{~F}_{\mathrm{a}} \mathrm{W} .\right. \\
& \cdot \cos (90-\alpha)]^{1 / 2}=0.03 \cdot 10.43=0,313[\mathrm{~N}]
\end{aligned}
$$

where: $-\mu_{\mathrm{s}}=0.05$ is the static friction coefficient in greasy friction conditions for aluminum, provided by SolidWorks software;
- $\mu_{\mathrm{k}}=0.03$ is the kinematic friction coefficient in greasy friction conditions for aluminum;

- $\mathrm{N}$ is the normal reaction force between the shaft and the bearing, computed, for example, for the angle $\alpha=45^{\circ}$.

Figure 7 shows the geometrical model of a revolute kinematical joint. The components material is Alumina, chosen from SolidWorks materials library.

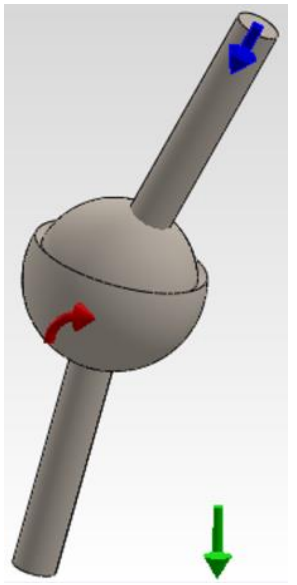

Fig. 7. 3D model of a spherical kinematical joint.

In SolidWorks Motion module, between the sphere and the spherical shell there is defined a Solid Body Contact, with the same kinematic friction coefficients used in relations (8) and (9).

The shaft is set to move with an angular speed of $\pi / 3[\mathrm{rad} / \mathrm{s}$ ], e.g. $120[\% \mathrm{~s}]$, in a period of $0.5[\mathrm{~s}]$.

The gravity is also applied in this case.

Figure 6 shows the variation of friction force, obtained after simulation.

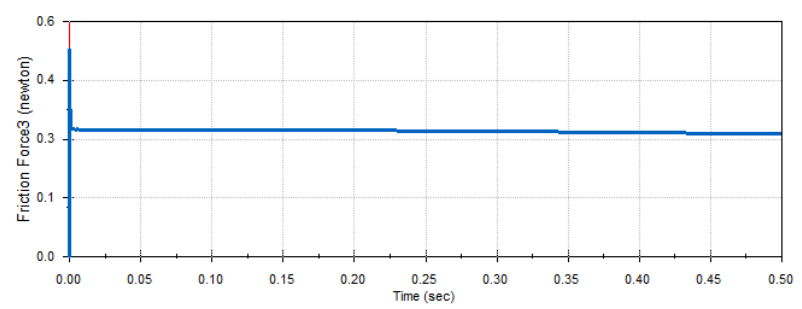

Fig. 8. The variation of friction force between the sphere and the spherical shell in simulation.

The friction force obtained by simulation has a value of $0.526[\mathrm{~N}]$ in static conditions, at the beginning of motion, close to the computed value of $0.522[\mathrm{~N}]$ from calculus (8), and a value in motion of $0.316[\mathrm{~N}]$ for the position $\alpha=45^{\circ}$, very close to the computed value of $0.313[\mathrm{~N}]$ from calculus (6). The exact values of friction force in simulation are taken from a .csv file provided by SolidWorks software.

\section{Conclusions}

The results of calculus and simulations are shown in table 1 . 
Table 1. Results comparison

\begin{tabular}{|c|c|c|c|c|c|}
\hline \multirow{2}{*}{$\begin{array}{l}\text { Crt. } \\
\text { no. }\end{array}$} & \multirow{2}{*}{$\begin{array}{l}\text { Joint } \\
\text { type }\end{array}$} & \multirow{2}{*}{ State } & \multicolumn{2}{|c|}{$\begin{array}{l}\text { Value of friction } \\
\text { force }[\mathrm{N}]\end{array}$} & \multirow{2}{*}{$\begin{array}{c}\text { Percent } \\
\text { relative } \\
\text { difference } \\
{[\%]}\end{array}$} \\
\hline & & & Calculus & Simulation & \\
\hline \multirow{2}{*}{1.} & \multirow{2}{*}{$\begin{array}{l}\text { Planar } \\
\text { surfaces }\end{array}$} & Static & 22946 & 21704 & 5.41 \\
\hline & & Motion & 19122 & 19120 & 0.01 \\
\hline \multirow[b]{2}{*}{2.} & \multirow{2}{*}{$\begin{array}{l}\text { Revolute } \\
\text { joint }\end{array}$} & Static & 0.810 & 0.787 & 2.84 \\
\hline & & Motion & 0.504 & 0.523 & -3.77 \\
\hline \multirow[b]{2}{*}{3.} & \multirow{2}{*}{$\begin{array}{l}\text { Spherical } \\
\text { joint }\end{array}$} & Static & 0.522 & 0.526 & $-0,77$ \\
\hline & & Motion & 0.313 & 0.316 & -0.96 \\
\hline
\end{tabular}

It can be observed that the values of calculus and simulation results are very close. The differences occur due to computing approximations.

On these considerations, the use of numerical simulation in the manner presented is an option that must be considered in order to evaluate the friction forces that occur in the kinematical joints of mechanical systems.

\section{References}

[1] Chernous'ko F.L., Shunderyuk M.M.: "The influence of friction forces on the dynamics of a two-link mobile robot", PMM Journal of Applied Mathematics and Mechanics, Vol. 74, Issue 1, pp13-23, 2010, DOI: 10.1016/j.jappmathmech.2010.03.003.

[2] Cojocaru V., Campian C.V., Korka Z.I.: „The Influence of Pressure Distribution on the Maximum Values of Stress in FEM Analysis of Plain Bearings", Robotica \& Management, vol. 21, no. 2, 2016, pp. 15-17.

[3] Cojocaru V., Micloşină C.-O.: „Numerical Analysis of the Influence of Clearance on Stress State and Contact Pressure in Plain Bearings", Robotica \& Management, Vol. 22, No. 2, December 2017, pp. 4-7.

[4] Corral E., Gomez Garcia M.J., Castejon C., Meneses J., Gismeros R.: "Dynamic Modeling of the Dissipative Contact and Friction Forces of a Passive Biped-Walking Robot", Applied Sciences-Basel, vol. 10, issue7, article no. 2342, 2020, DOI: 10.3390/app10072342.

[5] Jatsun S.F., Volkova L.Y., Naumov G.S., Yatsun A.S.: "Modelling of Movement of the Three-Link Robot with Operated Friction Forces on the Horizontal Surface", Proceedings of Conference on Climbing and Walking Robots (CLAWAR), July 14-17, 2013, Sydney, Australia, published in Nature Inspired Mobile Robotics, pp. 677-684, 2013.

[6] Jeon S., Tomizuka M.: "Limit cycles due to friction forces in flexible joint mechanisms", Proceedings of IEEE/ASME International Conference on Advanced Intelligent Mechatronics, 24-28 July, 2005, Monterey, CA, pp. 723-728.

[7] Kim S., Lee D.Y.: "Friction-Model-Based Estimation of Interaction Force of a Surgical Robot", Proceedings of the 15th International Conference on Control, Automation and Systems (ICCAS), October 13-16, 2015, Busan, South Korea, pp.1503-1507.

[8] Liu M., Quach N.H.: "Estimation and compensation of gravity and friction forces for robot arms: Theory and experiments", Journal of Intelligent \& Robotic Systems, vol. 31, issue 4, pp. 339-354, 2001, DOI: 10.1023/A:1012089607929.
[9] Liu X., Zhao F., Mei X.S.: "End-Effector Force Estimation for Flexible-Joint Robots with Global Friction Approximation Using Neural Networks", IEEE Transactions on Industrial Informatics, 15 (3), pp.1730-1741, 2019.

[10] Ludema K.C.: "Friction, Wear, Lubrication. A Textbook in Tribology", CRC Press, 1996.

[11] Miclosina C.: "Contributii la analiza si sinteza mecanismelor robotilor cu topologie paralela, utilizand notiunea de "conexiune"/Contributions to the Analysis and Synthesis of Parallel Topology Robots Mechanisms, Using the Notion of "Connexion"”, Doctor Thesis, "Politehnica" University of Timisoara, 2006.

[12] Miclosina C.-O.: "Roboti industriali si linii flexibile / Industrial Robots and Flexible Lines", Editura Eftimie Murgu, Resita, 2009.

[13] Miclosina C.-O., Campian C.V.: "3D Modeling and Motion Simulation of the Guiding Device of a Parallel Topology Robot", Robotica \& Management, vol. 15, no. 2, pp. 22-25, 2010.

[14] Miclosina C.-O., Korka Z.-I., Cojocaru V.: „Evaluation by Simulation of Reaction Forces that Occur in Spherical Joints of Parallel Topology Robots", Joint International Conference of the International Conference on Mechanisms and Mechanical Transmissions and the International Conference on Robotics - MTM \& Robotics 2020, Timişoara, Romania, published in Mechanisms and Machine Science book series, Volume 88, New Advances in Mechanisms, Mechanical Transmissions and Robotics, Springer, 2021, pp. 226-234, https://doi.org/10.1007/978-3-030-60076-1_20.

[15] Neglia S.G., Culla A., Fregolent A.: „Non-linear Dynamics of Jointed Systems Under Dry Friction Forces", Kerschen G. (ed.), Nonlinear Dynamics, Vol. 1, Conference Proceedings of the Society for Experimental Mechanics Series, Springer, Cham, 2016, DOI: 10.1007/978-3-319-15221-9_2.

[16] Vela I., Miclosina C.: "Cercetări în domeniul Roboticii la Universitatea "Eftimie Murgu" Reşiţa", (Research in the Field of Robotics at "Eftimie Murgu" University Resita), Robotica \& Management, Vol. 7, No. 1, June 2002, pp. 53-62.

[17] Vela I., Miclosina C., Vela D.G., Cojocaru V., Amariei D., Bizau V.: "Activities in Robotics Domain at „Eftimie Murgu” University of Resita”, Robotica \& Management, Vol. 14, No. 2, December 2009, pp. 33-35. [18] Vorochaeva L.Y., Naumov G.S., Yatsun S.F.: "Simulation of motion of a three-link robot with controlled friction forces on a horizontal rough surface", Journal of Computer and Systems Sciences International, vol. 54, issue 1, pp. 151-164, 2015, DOI: 10.1134/S1064230715010128.

[19] Vorochaeva L.Y., Panovko G.Y., Savin S.I., Yatsun A.S.: "Movement Simulation of a Five-Link Crawling Robot with Controlled Friction Forces", Journal of Machinery Manufacture and Reliability, vol. 46, issue 6, pp. 527-535, 2017, DOI: 10.3103/S1052618817060152.

[20] ***: "Friction and Friction Coefficients", https://www.engineeringtoolbox.com/frictioncoefficients-d_778.html 